\title{
Considerações Sobre a Formação de Professores do Ensino Fundamental de Turno Único na Rede Estadual do Paraná
}

\section{Considerations about the Teachers Training of Elementary of Single Shift in the State Network of Paraná}

\author{
Belmiro Marcos Beloni*a; Antonio Carlos Frasson ${ }^{\text {b; }}$, Alessandra Dutra ${ }^{\text {bc }}$; Merielle Camilo ${ }^{\mathrm{d}}$
}

aUniversidade Tecnológica Federal do Paraná. PR, Brasil.

bUniversidade Tecnológica Federal do Paraná, Programa de Pós-Graduação Stricto Sensu em Ensino de Ciência e Tecnologia. PR, Brasil. 'Universidade Tecnológica Federal do Paraná, Programa de Pós-Graduação Stricto Sensu em Ensino de Ciências Humanas, Sociais e da Natureza. PR, Brasil. dSecretaria de Estado da Educação e do Esporte. PR. Brasil.

*E-mail: belmirobeloni@gmail.com.

\begin{abstract}
Resumo
A oferta de Ensino Integral é consolidada como uma das melhores estratégias na busca de atendimento pleno da Educação Pública no Brasil, especialmente, com o intuito de alcançar educandos em situação de vulnerabilidade social. Historicamente, os programas de Governo se estruturaram na tentativa de agregar atendimento que extrapola o atendimento educacional, congregando outras esferas de serviços públicos, com enfoque no público mais vulnerável, com a oferta escolar em turno e contraturno. O ensino de turno único, desde 2012, propõe enfoque específico com reconfiguração da matriz curricular do Ensino Fundamental, com formato integrado de oferta das disciplinas. O objetivo foi discutir o Ensino Integral, tanto seu percurso histórico no Brasil como na política educacional de implementação no Paraná. Para a realização desse estudo se adotou pesquisa bibliográfica na literatura produzida sobre o tema, bem como nos documentos oficiais que nortearam suas implementações. Com o estudo se tornou visível que as políticas educacionais, em suas propostas, que modificam sobremaneira as estruturas de escolas e matrizes curriculares destinam vagas conceituações quando referente aos responsáveis in loco pela execução dessas políticas, tornando evidente que a diferenciação da oferta, impreterivelmente, deve ser para além do prolongamento da jornada escolar. A consolidação do programa, enquanto permanente, demanda formação continuada para professores que atuam, diferente da generalizada para toda a rede de Ensino Estadual, fator de impacto determinante no sucesso de sua execução e ampliação de atendimento.
\end{abstract}

Palavras-chave: Educação Básica. Educação Integral. Formação Continuada.

\begin{abstract}
The offer of full-time education is consolidated as one of the best strategies in the search for full service to public education in Brazil, especially with the aim of reaching students in situations of social vulnerability. Historically, government programs have been structured in an attempt to aggregate care that goes beyond educational care, bringing together other spheres of public services, with a focus on the most vulnerable public, with the school supply in shift and second shift. The single shift teaching since 2012, proposes a specific approach with the curricular matrix reconfiguration of elementary education, with an integrated format for offering subjects. The objective was to discuss full-time education, both its historical trajectory in Brazil and in the educational implementation policy in Paraná. To carry out this study, bibliographic research was adopted in the literature produced on the theme, as well as in the official documents that guided its implementations. With the study it became visible that the educational policies in their proposals that greatly modify the schools and matrices curricula structures aim at vague conceptualizations when it comes to those responsible in loco for the implementation of such policies, making it evident that the offer differentiation must be beyond the school day extension. The program consolidation, while permanent, requires continued training for teachers who work, different from the generalized for the entire state education network, a determining impact factor in the success of its execution and attendance expansion.
\end{abstract}

Keywords: Elementary Education. Full-time Education. Continuing Training.

\section{Introdução}

A oferta da Educação Integral, desde os primórdios da estruturação do ensino, é tida como umas melhores possibilidades de solução para a histórica defasagem de conhecimentos das classes populares no Brasil. Tornou-se assim inquestionável que passar mais do que as costumeiras cinco horas/aula, para criança e adolescente, em um ambiente voltado exclusivamente para a educação se tornaria a panaceia para os problemas educacionais e sociais.

Torna-se preponderante tomar como ponto de partida as iniciativas de Anísio Teixeira, a quem se pode tributar inquestionável influência virtuosa na Educação brasileira, especialmente com a Escola-Parque, proposta em Salvador na década de 1950. Em conformidade com tal trajetória de Ensino Integral na oferta integral, não será tratado aqui contraturno escolar ou iniciativas públicas e/ou privadas que trabalhem sem matriz curricular desta.

Sendo assim, a proposta da Educação e mesmo da escola que trabalha em turno único, nomenclatura adotada no Paraná, necessita firmemente de um propósito pedagógico, integrando temporalidade, espaço e conteúdos em que os participantes tenham visíveis os objetivos a serem perseguidos.

Nesse sentido, todo projeto interdisciplinar competente surge de um locus bem delimitado, pois é preciso apreender 
o contexto para construir significado. Contextualizar exige recuperação da memória em suas diferentes potencialidades, do tempo e do espaço no qual se aprende. A análise conceitual facilita a compreensão de elementos interpretativos do cotidiano (FAZENDA, 2011).

Torna-se completamente improdutivo realizar qualquer reflexão acerca de ensino de matriz curricular integral, no qual não ocorra desde sua concepção teórica a pretensão de sinergia interdisciplinar, sendo que esta somente se materializa, ou ainda, acontece em sala de aula, quando é firmemente entrelaçada com a formação de professores das diferentes disciplinas curriculares.

Ainda, cabe situar aqui, educação integral como manifestação da responsabilidade do Estado e da responsabilidade deste no tocante à educação pública, inserida na perspectiva de qualidade dos serviços que este deve proporcionar à população, enquanto direitos sociais. Diante disso, esta se transfigura enquanto maneira de evidências as múltiplas determinações e possibilidades que constituem o desenvolvimento do educando.

Dentro dessa perspectiva, o alargamento do tempo na escola pode refletir a existência efetiva de políticas educacionais que distinguem as diferentes temporalidades colocadas na e para escola, subsidiando trabalhos que, por um prisma, revelam que a primazia excessiva da escola no tempo do educando e, de outro que essa extensão se associa, historicamente, às reivindicações de educadores, na busca por melhor atendimento das necessidades das condições da vida atual (ARCO-VERDE, 2012).

Dentro de demandas diferentes estruturalmente se torna pressuposto a distinção ou mesmo ampliação de estruturas de formação de profissionais, bem como a diferenciação dos ambientes formativos que o estabelecimento educacional que efetivará esse ensino. Para tal, a oferta de educação integral requer a concentração acentuada de recursos cognitivos, relacionais, afetivos, psicomotores e sociais; em nova organização de currículo conectada para recuperar a integralidade, no aumento e pluralidade das práticas e experiências de aprendizagem, bem como no fluxo do maior número de ambientes diversificados, na busca de integralização de saberes e experiências (SETUBAL; CARVALHO, 2012).

Por não se tratar somente de aumento no número de aulas ou atividades, de redimensionamento de carga horária na matriz curricular, com dezenas de disciplinas a mais, especificamente no Ensino Fundamental, sem quaisquer conexões entre os conteúdos e disciplinas tradicionais e as novas disciplinas, torna-se elementar a formação de professores especificamente para a atuação no ensino de sexto a nono ano.

Focalizando na formação docente, esse artigo propõe discutir a trajetória da implementação do ensino fundamental de turno único no estado do Paraná, em estabelecimentos que anteriormente ofertavam ensino fundamental na organização tradicional com cinco horas/aula.

\section{Desenvolvimento}

\subsection{Metodologia}

Ter como objeto de estudo algo mutável ou em constante reformulação não é tarefa fácil e implica uma dose de ousadia para tal. Quando esse objeto faz parte de um universo complexo, pois pretende sair de determinismos e angariar possibilidades para o para a educação de tempo integral. Segundo Ludke e André (2002), esta metodologia, possibilita a identificação de informações, desencadeadas de hipóteses de interesse, em um ou mais documentos. Essa definição deve obedecer a temporalidade da evolução dos dispositivos legais que desaguam no funcionamento das ofertas envolvidas, bem como nos caminhos da reconfiguração desta em propostas posteriores. Torna-se elementar, deter-se na análise dos documentos produzidos pelo Ministério da Educação e do Conselho Nacional de Educação e do Conselho Estadual de Educação, das diretrizes estaduais atualmente que amparam a educação integral de turno único, bem como das iniciativas para a formação de professores para essa especificidade.

\subsection{Breve histórico do Ensino Integral no Brasil}

Anísio Teixeira, com base nos estudos que desenvolvera sobre o pragmatismo de John Dewey, procurou materializar suas perspectivas de educação integral na criação do Centro Educacional Carneiro Ribeiro, na capital da Bahia, 1950.

Segundo o autor:

A filosofia da escola visa a oferecer à criança um retrato da vida em sociedade, com as suas atividades diversificadas e o seu ritmo de "preparação" e "execução", dando-lhe as experiências de estudo e de ação responsáveis. Se na escolaclasse predomina o sentido preparatório da escola, na escolaparque, nome que se conferiu ao conjunto de edifícios de atividades de trabalho, sociais, de educação física e de arte, predomina o sentido de atividade completa, com as suas fases de preparo e de consumação, devendo o aluno exercer em sua totalidade o senso de responsabilidade e ação prática, seja no trabalho, que não é um exercício, mas a fatura de algo completo e de valor utilitário, seja nos jogos e na recreação, seja nas atividades sociais, seja no teatro ou nas salas de música e dança, seja na biblioteca, que não é só de estudo, mas de leitura e de fruição dos bens do espírito (TEIXEIRA, 1962, p. 6).

Dentro desta visão, utiliza-se não somente um caráter transmissivo da educação vislumbra-se, especialmente tratando-se do ensino público que atende as classes populares, uma aliança entre o conhecimento científico e a prática, proporcionando complementariedade entre o ensino de sala de aula (escola-classe), com a aplicabilidade e experimentação (escola-parque). O arcabouço teórico que Anísio Teixeira utilizou, bem como o resultado de sua iniciativa, tornou-se o referencial para a construção das políticas de educação integral no Brasil naquele contexto histórico e, marcou definitivamente as propostas que viriam adiante.

Com relevância equivalente, porém com capilaridade mais abrangente, os CIEPs - Centros Integrados de Educação 
Pública protagonizaram nos anos de 1980 a iniciativa de Darcy Ribeiro no Rio de Janeiro, sendo de fato a primeira experiência governamental, ou seja, de escola pública de tempo integral. Esses estabelecimentos foram construídos preferencialmente, nas regiões daquele estado onde se concentravam contingentes populacionais vulneráveis economicamente. O objetivo de atendimento era o ensino de $1^{\circ}$ grau (atual ensino fundamental) com complemento de estudos dirigidos e "atividades como esportes e participação em eventos culturais, numa ação integrada que objetiva elevar o rendimento global de cada aluno" (RIBEIRO, 1986, p.42).

Para além da proposta de escola-parque ou escola-classe, o CIEP é colocado como uma escola-casa, pois tem o objetivo respeitar os direitos das crianças. Preconizando isso, defende que desnutrição, falta de material escolar, doenças infecciosas, problemas dentários, visuais e auditivos, sejam de fato as causas de baixo rendimento e evasão escolar. Justificando que nestes Centros se tenha atendimento médico e odontológico, considerando que tal política seja adequada a realidade de exclusão e não paternalista (PARO et al, 1988, p. 20).

É relevante citar, entretanto, com menor impacto, a criação no início dos anos noventa, dos CAICs (Centro de Atenção Integral à Criança), que surge como política do Governo Federal, que anuncia a construção de 5 mil unidades, com o mesmo projeto arquitetônico, sendo que, ao final do mandato são construídas 444 unidades. Atualmente, a imensa maioria não oferta educação integral, tendo sido entregues para a responsabilidade de governos municipais e estaduais. Exemplo disso é o fato que de 44 CAICs em território paranaense, somente a unidade de Ponta Grossa oferta Ensino Integral, nas séries iniciais do Ensino Fundamental e parcial para as séries finais do mesmo. O projeto arquitetônico dos CAICs era mesmo por duas razões:

A primeira razão foi econômica: um projeto arquitetônico adrede elaborado incorporou-se às condições mediante as quais foram licitadas as construções das unidades. Como as estruturas foram concebidas em peças pré-moldadas, produzidas em série, em seguida transportadas e montadas nos locais determinados, o parâmetro construtivo ensejou a instalação de unidades fabris (as 'fábricas de CAICS') em locais estratégicos, garantindo qualidade uniforme e óbvia economia de meios. Outro critério prendeu-se ao interesse de caracterizar o Programa em âmbito nacional, já a partir de sua base física, como algo novo, diferente das habituais iniciativas em educação e outros segmentos da infraestrutura social. Não se construíam apenas escolas, porém unidades multissetoriais que iriam além dos modelos tradicionais e apresentar-se-iam, até na forma arquitetônica, como algo distinto do então conhecido (PONTES, 1997, p.4).

No entanto, mesmo com essa identidade garantida, a ausência de responsabilidade centralizada pelo programa, que começou coordenado pela extinta LBA - Legião Brasileira de Assistência, passou pela Secretaria de Projetos Especiais da Presidência da República e somente após dois anos em execução ficou a cargo do Ministério da Educação, sendo que para operacionalizá-lo demandava muito mais dos entes municipais e estaduais do que propriamente da União, que praticamente se encarregou apenas da construção das unidades.

As três iniciativas governamentais aqui expostas, bem como dezenas de outras em âmbitos locais e estaduais, com maior frequência nas últimas duas décadas, fortalecem a premissa de que, em sua grande maioria, os Programas de Governo são descontinuados ou no melhor cenário, fragmentados, sem que sejam reavaliados ou redimensionados por Governos ou gestões posteriores.

\subsection{Educação Integral de Turno Único no Paraná}

Como parte do Plano de Metas do Governo do Paraná no período entre 2011 e 2015, a Educação Integral de Turno Único pretende, segundo o documento orientador da Secretaria de Estado da Educação sem a distinção de turno e contraturno. Iniciou-se a implantação por adesão dos estabelecimentos a partir de 2012, em 4 estabelecimentos, chegando a 27 no ano seguinte, sendo ampliado posteriormente para 56 escolas em 2017, nas diferentes regiões do Estado.

Da totalidade de escolas que por iniciativa se habilitaram para a oferta, 42 dispõem de Ensino Fundamental integral, 9 Ensino Médio e 4 atendem Ensino Fundamental e Médio.

Conforme se verifica na Figura 1, a distribuição dos estabelecimentos que aderiram ao Ensino Integral de Turno Único não obedece a qualquer critério de densidade populacional, sendo que Francisco Beltrão e Pato Branco por demandas específicas concentram mais de um quinto dos estabelecimentos. Isso se justifica pela adesão por parte dos estabelecimentos estaduais, independer da região do Estado, mas principalmente das condições de infraestrutura e de número de estudantes matriculados, obedecendo a possibilidade de implantação total (imediata em todas as séries) ou gradual (a partir do $6^{\circ}$ ano).

Figura 1 - Distribuição dos estabelecimentos que ofertam Educação Integral no Paraná por Núcleos Regionais de Educação

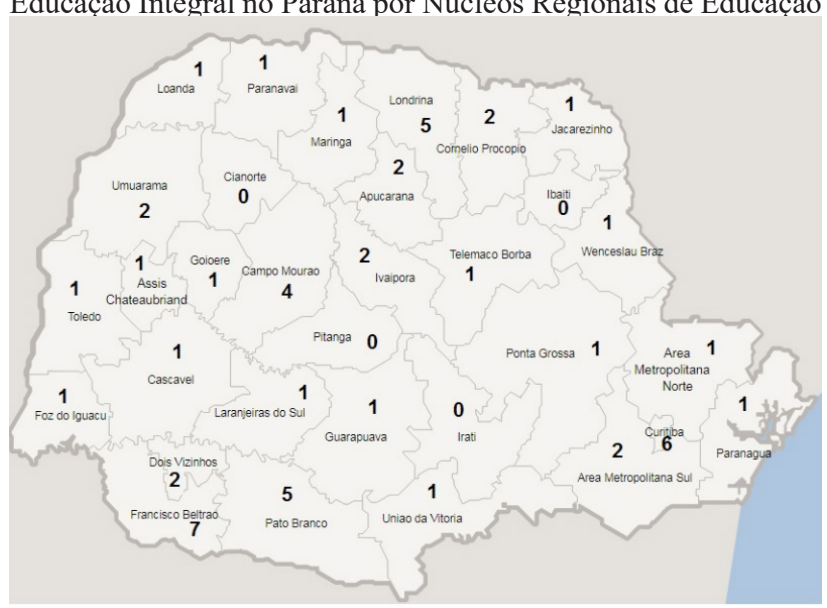

Fonte: Paraná (2017).

De acordo com o documento que subsidia a elegibilidade facultativa de estabelecimentos para essa organização

$\mathrm{O}$ que se pretende então, é que a Educação em Tempo 
Integral não proponha a superação do ensino organizado por disciplinas, mas a criação de condições de ensinar em função das relações dinâmicas entre as diferentes disciplinas com o diferencial do maior tempo para desenvolver conteúdos que estejam sistematizados e articulados com o currículo da escola, fruto de um planejamento adequado e não da realização de atividades que sejam produtos de improvisação e do acaso (PARANÁ, 2012, p.15).

A implantação do turno único obedece a algumas determinações e entre essas já dispor de infraestrutura adequadas ou de viável adequação para receber o Ensino Integral, que dispõe de suas aulas de manhã e tarde, com intervalo para almoço, perfazendo 45 horas/aula de carga horária semanal e 1800 horas/aula anuais, tendo o Ensino Fundamental 7200 h/a de curso.

Fica claro que a iniciativa centrada nesse documento da SEED dimensiona a oferta partindo primeiro da disponibilidade do estabelecimento e das condições de infraestrutura do mesmo, quando diverge das experiências de Ensino Integral já praticadas (especialmente, na dinâmica turno e contraturno). Contudo, tal proposta, que vigora nos últimos cinco anos não discute diretamente sobre a formação do quadro docente que implementará de fato tal ensino.

A principal mudança realizada pela escola, a mudança dos seus documentos institucionais, especificamente, o Projeto Político-Pedagógico e a Proposta Pedagógica Curricular, precisam no ano anterior a sua implementação serem modificadas contemplando essa nova realidade de oferta do Ensino Fundamental.

De acordo com o Quadro 1, a ampliação da carga de 25 para 45 h/a se fundamenta no aumento da Parte Diversificada (que na matriz tradicional tem somente Língua Estrangeira Moderna - LEM). Essa matriz, de acordo com a Instrução 07/2017 da SEED-PR, é configurada por estabelecimento, sendo que 28 h/a são para as disciplinas da Base Nacional Comum e 17h/a para a Parte Diversificada, sendo que 11 $\mathrm{h} / \mathrm{a}$ são para disciplinas escolhidas pela comunidade escolar, 3h/a para LEM e $3 \mathrm{~h} / \mathrm{a}$ para Componentes Curriculares que são atividades planejadas e dirigidas, porém não atendem aos requisitos de se constituir como uma disciplina, sempre ofertada no último horário do dia.

Quadro 1 - Disciplinas da Parte Diversificada e Disciplinas Tradicionais às quais estão vinculadas. - Ensino Fundamental Séries Finais

\begin{tabular}{|c|c|c|c|}
\hline $\begin{array}{l}\text { Disciplina } \\
\text { Vinculada }\end{array}$ & Título da Disciplina & $\begin{array}{c}\text { C H } \\
\text { Sugerida }\end{array}$ & $\begin{array}{c}\text { Anos } \\
\text { Sugeridos }\end{array}$ \\
\hline \multirow{3}{*}{ Arte } & Educação Musical & 02 & $6^{\circ}$ ao $9^{\circ}$ \\
\hline & Audiovisual na Arte & 02 & $8^{\circ}$ e $9^{\circ}$ \\
\hline & Dança & 02 & $6^{\circ}$ e $7^{\circ}$ \\
\hline \multirow{3}{*}{ Ciências } & Educação Científica e Cidadania & 02 & $6^{\circ}$ ao $9^{\circ}$ \\
\hline & Atividades Experimentais & 02 & $8^{\circ}$ e $9^{\circ}$ \\
\hline & Astronomia & 02 & $6^{\circ}$ ao $9^{\circ}$ \\
\hline \multirow{2}{*}{ Educação Física } & Aprofundamento Esportivo & 03 & $6^{\circ}$ ao $9^{\circ}$ \\
\hline & Vivência Corporal & 03 & $6^{\circ}$ e $7^{\circ}$ \\
\hline \multirow{3}{*}{ L.E.M. } & Leitura e Informação em Língua Espanhola & 02 & $6^{\circ}$ ao $9^{\circ}$ \\
\hline & Inglês Online & 02 & $6^{\circ}$ e $7^{\circ}$ \\
\hline & O Inglês na Literatura e no Cinema & 02 & $8^{\circ}$ e $9^{\circ}$ \\
\hline \multirow{2}{*}{ Língua Portuguesa } & Literatura Infantojuvenil & 03 & $6^{\circ}$ ao $9^{\circ}$ \\
\hline & Mídia e suas Linguagens & 03 & $6^{\circ}$ ao $9^{\circ}$ \\
\hline \multirow{2}{*}{ Matemática } & Laboratório de Matemática & 02 & $6^{\circ}$ ao $9^{\circ}$ \\
\hline & Matemática Financeira & 02 & $6^{\circ}$ ao $9^{\circ}$ \\
\hline \multirow{2}{*}{ Sociologia } & Noções Sociológicas: Identidade, Juventude e Sociedade & 02 & $8^{\circ}$ e $9^{\circ}$ \\
\hline & Mídia e Sociedade & 02 & $8^{\circ}$ e $9^{\circ}$ \\
\hline \multirow{2}{*}{ Geografia } & Dinâmica Climática & 02 & $6^{\circ}$ e $7^{\circ}$ \\
\hline & Espaço Cultural Paranaense & 02 & $6^{\circ}$ ao $9^{\circ}$ \\
\hline \multirow{2}{*}{ História } & Arqueologia e Patrimônio Histórico & 02 & $6^{\circ}$ ao $9^{\circ}$ \\
\hline & Narrativas Históricas Audiovisuais & 02 & $6^{\circ}$ ao $9^{\circ}$ \\
\hline \multirow{2}{*}{ Filosofia } & Conhecimento e Lógica & 02 & $6^{\circ}$ e $7^{\circ}$ \\
\hline & Iniciação ao Pensar Filosófico & 02 & $8^{\circ}$ e $9^{\circ}$ \\
\hline $\begin{array}{l}\text { Língua; Linguagens e } \\
\text { Códigos }\end{array}$ & Libras & 02 & $6^{\circ}$ ao $9^{\circ}$ \\
\hline
\end{tabular}

Dentro dessa premissa, os Componentes Curriculares têm sua oferta vinculada à demanda do estabelecimento para o enfoque preferencial, discutido com a comunidade escolar, sendo discutido periodicamente pelas instâncias colegiadas, visando sempre a mudança dinâmica dos momentos formativos, adaptando-se às realidades de estudantes, sendo indispensável que sua implementação e integralização municie estudantes com possibilidades de ampliação de suas condições de aprendizagem.

Os Componentes Curriculares são organizados da seguinte 
forma:

Quadro 2 - Organização dos Componentes Curriculares e respectivas áreas

\begin{tabular}{|c|c|}
\hline Áreas & Componente Curricular \\
\hline \multirow{4}{*}{$\begin{array}{l}\text { Acompanhamento/ } \\
\text { Aprofundamento } \\
\text { Pedagógico }\end{array}$} & Ciências \\
\hline & História e Geografia \\
\hline & Língua Portuguesa \\
\hline & Matemática \\
\hline \multirow{4}{*}{ Esporte e Lazer } & $\begin{array}{l}\text { Iniciação ao Desporto (esportes } \\
\text { individuais e (coletivos) }\end{array}$ \\
\hline & Lutas \\
\hline & Ginástica artística e/ou Rítmica \\
\hline & Recreação e Lazer \\
\hline \multirow{3}{*}{$\begin{array}{l}\text { Temas Sociais } \\
\text { Contemporâneos }\end{array}$} & Educação em Direitos Humanos \\
\hline & $\begin{array}{l}\text { Educação Ambiental e Desenvolvimento } \\
\text { Sustentável }\end{array}$ \\
\hline & $\begin{array}{l}\text { Promoção da saúde e Prevenção de } \\
\text { Doenças }\end{array}$ \\
\hline \multirow{4}{*}{$\begin{array}{l}\text { Cultura, Arte } \\
\text { e Educação } \\
\text { Patrimonial }\end{array}$} & Artes Visuais \\
\hline & Música \\
\hline & Expressão Corporal \\
\hline & Cultura e Patrimônio \\
\hline \multirow{3}{*}{$\begin{array}{l}\text { Comunicação e Uso } \\
\text { de Mídias }\end{array}$} & $\begin{array}{l}\text { Tecnologias da Informação e } \\
\text { Comunicação }\end{array}$ \\
\hline & Jornal Escolar \\
\hline & Rádio Escolar \\
\hline
\end{tabular}

Fonte: Paraná (2012).

Tanto as atribuições de aula, quanto de componentes curriculares se tornaram uma novidade na rotina de professores que estão habituados em organização de currículo, que salvo poucas mudanças de carga horária não haviam sofrido reconfiguração, com transformação de conteúdos abordados dentro das disciplinas tradicionais em novas disciplinas.

Sustentando-se em um ensaio de Pedro Demo sobre o tema, a Secretaria de Educação define:

Não há como falar em disciplina curricular sem considerá-la como saber que apresenta determinado nível de especialidade, caso contrário, sua existência não se justificaria enquanto relevante para a educação escolar. Essa condição, por sua vez, resulta que a disciplina escolar requeira a disponibilidade e a atuação de professores que dominem seu campo epistemológico, assim como detenham e pratiquem o saber didático- pedagógico concernente a ela, ou seja, saibam ensiná-la. Espera-se, portanto, que os profissionais agreguem tanto o conhecimento dos conteúdos/saberes da disciplina que ensinam quanto detenham os conhecimentos requeridos pelo ato pedagógico da elaboração e do desenvolvimento dos encaminhamentos metodológicos necessários para que o processo de ensino-aprendizagem se efetive (PARANÁ, 2012, p.17).

Inversamente ao defendido na normativa acima, a distribuição das aulas apenas coloca como diferencial ou preferência na escolha para o profissional que tenha participado em cursos ofertados pela mantenedora sobre o assunto e/ou que tenha preferência quem possui maior tempo de serviço na Educação em Tempo Integral. Vale ressaltar que disciplinas como Filosofia e Sociologia, em grande parte dos currículos, contempla somente estágio no Ensino Médio, sendo que algumas disciplinas da Parte Diversificada, prioritariamente, devem ser ministradas por licenciados nessas áreas.

Cabe salientar nesse ponto que, em pesquisa a homepage

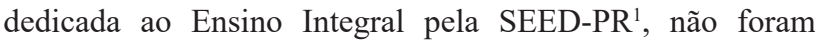
encontrados registros de eventos estaduais, bem como produções sobre oficinas tratando do Ensino Fundamental em turno único. Somente, na Semana Pedagógica² no início de 2017, formação no local de trabalho, com temas direcionados pela mantenedora, foram encaminhados alguns textos para discussão mais específica, momento aquele em que cerca de 20 estabelecimentos iniciavam a gradativa mudança para o integral.

Denota-se, nesse contexto, que a formação continuada de professores é oportunizada de maneira generalista, sem atender essa especificidade. Explicita que a competência e eventuais preparações, para diferentes perfis de ensino e estudantes, cabem somente aos professores, que suas licenciaturas devem dar subsídio teórico e prático para disciplinas diferentes e abordagens próprias da Educação Integral.

Em sentido oposto:

A educação integral dos alunos pressupõe a educação integral dos professores, no sentido da superação da fragmentação do próprio ser humano e das antinomias entre formação geral e específica, humanista e tecnológica, científica e técnica. Como pode o professor realizar uma educação integral se ele mesmo se encontra dividido? Há uma contradição entre a formação e o trabalho que se revela mais evidente quando pensamos no processo educativo na escola de tempo integral e isso pode ser resolvido. A extração da face emancipatória da atividade educativa está inscrita na tensão permanente entre a formação do ser social 'em si' e 'para-si', ou seja, entre as finalidades particulares e os objetivos da genericidade humana (DUARTE, 2007).

A formação continuada de professores, necessariamente, deve ter uma íntima relação com o ambiente educativo, no qual o processo de ensino e aprendizagem se desvela. $\mathrm{O}$ sentido de identidade das escolas com a comunidade na qual está inserida revelada no Projeto Político-Pedagógico e na Proposta Pedagógica Curricular, que especificamente no caso desses 56 estabelecimentos de Educação Integral foram objeto de discussão e configuração próprias, remetem ao atendimento docente compatível. Encarar a formação continuada realizada de forma generalista, sem sequência e reavaliação do processo de implementação da política ou programa como suficiente, incorre em uma lacuna fundamental para qualidade e completude do atendimento.

1 http://www.educadores.diaadia.pr.gov.br/modules/conteudo/conteudo.php?conteudo=1532

2 http://www.gestaoescolar.diaadia.pr.gov.br/arquivos/File/sem_pedagogica/fev_2017/orientacao_sempedag_edtempointegral.pdf 


\section{Conclusão}

A história da Educação Integral no Brasil parte da premissa de que é indispensável sair do empírico para o científico na constituição do conhecimento por parte do aluno, diferenciando do monolitismo da educação tradicional tributária à organização confessional. A constituição do sentido de aprender, da aplicabilidade dos conhecimentos preconizada pelas primeiras propostas, invariavelmente, impingiram que o caminho da escola brasileira que resgataria as possibilidades de desenvolvimento nacional, passariam pela constituição de uma educação em tempo integral.

As políticas focalizadas nisso, nas últimas duas décadas do século XX, almejando buscar alcançar crianças e adolescentes, em situação desfavorável, abarcaram muito mais da educação formal em suas propostas, tornando-se um ambiente profícuo para execuções assistencialistas de início e, gradativamente, descontinuadas por serem políticas de mandato, para as quais carecem de avaliação responsável de gestores subsequentes, reconfiguração que visem aproveitamento do que já havia sido realizado.

A constituição das atividades em turno e contraturno, sem conexão com as atividades entre os dois torna muito vulnerável os objetivos e unicidade da oferta. Nesse sentido, o Ensino Integral de turno único acerta no sentido quando não cai na fragmentação ou parcelamento dos processos, procurando uma proposta interdisciplinar, em projeto.

Entretanto, fica inviabilizada a aplicabilidade de tal formato edificante e coeso, se ano após ano, professores e professoras, dependendo apenas de suas condições de formação inicial e protagonismo, forem responsáveis pela consolidação das conexões fundamentais para o sentido de integralidade. É impensável que docentes planejam e executem seus planos de trabalho sem levar em consideração a pertinência e as possibilidades que a Educação Integral podem proporcionar para o educando. Mesmo sendo um programa em expansão, por adesão, urge formação específica, sob o risco de execução parcelada, insuficiente e conforme a história mostra, com risco de se tornar obsoleta e, por fim, descontinuada.

\section{Referências}

ARCO-VERDE, Y.F.S. Tempo Escolar e organização do trabalho pedagógico. Arco Verde, 2012. doi: http://dx.doi. org/10.24109/2176-6673.emaberto.25i88.2587

DEMO, P. Escola de tempo integral. Textos Discutiveis, 11. 2018. Disponível em: http://pedrodemo.blogspot.com.br/search?q=integral. Acesso em: 2 nov. 2020.

DUARTE, N. Educação escolar, teoria do cotidiano e a escola de Vygotsky. Campinas: Autores Associados, 2007.

FAZENDA, I.C.A. Integração e interdisciplinaridade no ensino brasileiro: efetividade ou ideologia. São Paulo: Edições Loyola, 2011.

LUDKE, M.; ANDRÉ, M.E.D.A. Pesquisa em educação: abordagens qualitativas. São Paulo: EPU, 2002.

PARANÁ, Secretaria de Estado da Educação. Orientações para implementação da Educação Integral em Turno Único. Curitiba: SEE, 2012

PARANÁ, Secretaria de Estado da Educação. Instrução Normativa 07. Curitiba: SEE, 2017.

PARO, V H.; FERRETI, C.J.; VIANNA, C.P.; SOUZA, D.T. Escola de tempo integral: desafio para ensino público. São Paulo: Cortez, 1988.

PONTES, M. A. D. A mitologia educacional. In: LDB: REFLEXÕES E CAMINHOS: CNEC - O DESAFIO DA EDUCAÇÃO COMUNITÁRIA. Brasília: INDEC, 1997.

RIBEIRO, D. O livro dos CIEPs. Rio de Janeiro: Bloch, 1986

SETÚBAL, M.A.; CARVALHO, M.C.B. Alguns parâmetros para a educação integral que se quer no Brasil. Em Aberto, v.25, n.88, 2012. doi: http://dx.doi.org/10.24109/2176-6673.emaberto. $25 \mathrm{i} 88.2589$

TEIXEIRA, A. Uma experiência de educação primária integral no Brasil. Rev. Bras. Estudos Pedagógicos. v.38, n.87, p.21-33. 1962. 